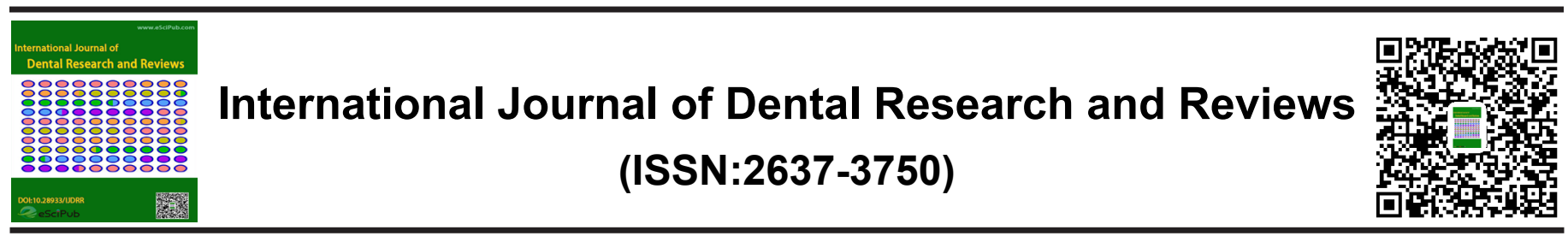

\title{
A new approach to root debridement: millimeter and furcation specific periodontal files
}

\author{
Henriques, $\mathrm{PSG}^{1}$; Azevedo $\mathrm{CL}^{2}$ \\ ${ }^{1}$ São Leopoldo Mandic, Institute and Dental Research Center, Campinas, SP Brazil. Professor \\ Head of Department; \\ ${ }^{2}$ University of São Paulo, Preventive Dentistry, São Paulo, Brazil. Master Degree Student
}

\begin{abstract}
The most commonly used procedure for root surface debridement is mechanical scaling and root planing using hand instruments. Periodontal files are used as a part of treatment introduced in subgingivally pockets. The difficult lies in stablishing an analogy of this depth measurement to the probe by a PCP 12 and the corresponding input of this files at the same distance. The authors present new files, similar to Hirschfeld, have been modified with external marking at $12 \mathrm{~mm}$, allowing the Periodontist this analogy, and facilitating the process.

On the other hand a specific small diameter PHenriques 6 and PHenriques 7 files, to instrument more easily this complex region. Consist of a series of 3 blades, and its sharp edges in 270 degrees around the active tip, reaching the root trunk, fornix and neighbor's surfaces. They are extremely useful especially in Class III involvement and sharpening in the same way as conventional files.
\end{abstract} *Correspondence to Author:

Paulo Sérgio Gomes Henriques Rua Hilário Magro Jr. 37, Cj 1. Zip Code13026-123, Campinas, São Paulo, Brazil;

How to cite this article:

Henriques, PSG; Azevedo CL. A new approach to root debridement: millimeter and furcation specific periodontal files. International Journal of Dental Research and Reviews, 2021, 4:46

Keywords: Periodontal files, cementum decontamination, gingieScîPub
eSciPub LLC, Houston, tx USA. Website: https://escipub.com/ val health 


\section{Introduction}

Bacterial plaque and calculus are recognized etiological agents in the initiation and progression of periodontal disease, whose accumulation and attachment are facilitated by a roughened root surfaces. The most commonly used procedure for root surface debridement is mechanical scaling and root planning(SRP) using hand instruments, although an abundance of research has demonstrated that SRP has limitations. For example, the effectiveness of calculus removal decreases substantially with increasing pocket depth. Despite our best efforts, calculus remains on tooth surfaces ranging from $17 \%$ to $64 \%$ after closed scaling and root planing and $7 \%$ to $24 \%$ after surgical intervention and open instrumentation by experienced operators ${ }^{[1]}$.Periodontal files are used on instrumentation of root surfaces as a part of periodontal treatment and its active angles and in sharpness probably have a significant influence on effectiveness of root instrumentation. ${ }^{[2]}$ File use in therapy will aid in reducing burnished or residual calculus and plaque-retentive, mainly for removing tenacious deposits from developmental depressions and grooves. ${ }^{[3]}$ Instrumentation with files has received considerable criticism because of the potential for creating root surface roughness and their inability to adapt subgingivally to root anatomy due to the bulky design. In fact, access with files with very narrow heads is better than scaler in some situations. Small working files have a narrower depth diameter than the scaler that promotes easy insertion into the periodontal pocket, especially with tight tissue tone. The mode of attachment of light calculus is sometimes tenacious and fine finishing files are advantageous. To minimize root surface roughness, the files should only be used to fracture large portions of calculus and to achieve the best results of a smooth and clean surface, we should start scanning with scaler, continue with the files and finally to finish the procedure with scaler and root planing. The blades of these instruments play an important role since they must present a width that allows correct and effective root debridement. ${ }^{[4]}$ However, narrow furcation entrance dimensions may complicate the periodontal treatment of furcation involvements as the active tip of most instruments (e.g.: Gracey scalers) present width of $0.95-1.2 \mathrm{~mm}$ and do not fit in the furcation region. ${ }^{[5]}$ The use of properly trained files should be encouraged in order to diminish the skepticism of this important hand instrument which, when well used, greatly contributes to the success of root cementum decontamination.

\section{Instruments presentation}

\section{1) THE FILES IN MILLIMETERS(mm):}

Periodontal instruments should be introduced in subgingivally pockets, from the gingival margin to the bone crest. The difficult lies in stablishing an analogy of this depth measurement to the probe by a PCP 12 and the corresponding input of this files at the same distance. These new files, similar to Hirschfeld, have been modified with external marking at $12 \mathrm{~mm}$, allowing the Periodontist this analogy, and facilitating the root scaling process. [Figures 1-2]

\section{2) THE PHenriques FILES 6 and 7 TO FURCATION:}

Each Hirschfeld file is composed of a head (body), shank, and handle. The round, oval, oblong or rectangular head contains multiple cutting edges that are adapted parallel to the calculus deposit and engaged, resulting in the fracturing of the calculus. The portion of the cutting edge facing the shank and handle, called the lip, is located at either a $90^{\circ}$ or $105^{\circ}$ angle with the shank. Rank angle refers to the distance between each lip that approximates $55^{\circ}$ depending on the design. Shanks of files are either straight or contra-angled, and vary in length and width to facilitate adaptation. Effective instrumentation of furcation defects have been always a challenge for periodontists due the limited accessibility through the furcation entrances as well as the complex anatomy and morphology of molar 
teeth. For those reasons, teeth with furcation involvement in periodontal disease have been shown a poorer prognosis than teeth without furcation involvement. According to previous studies, root trunk dimensions play an important role in the periodontal disease process due to its significant relation to both prognosis and treatment of the tooth. Concerning the furcation entrance dimensions, a high percentage of mandibular first molars have width values equal to or less than $0.75 \mathrm{~mm}$. These values are smaller than the width of common curettes, which means that such instruments do not clean appropriately the dental surface in the furcation entrance area. Thus, the effectiveness to instrument the furcation entrance area is compromised because such scalers do not fit in this area. ${ }^{[4,5]}$

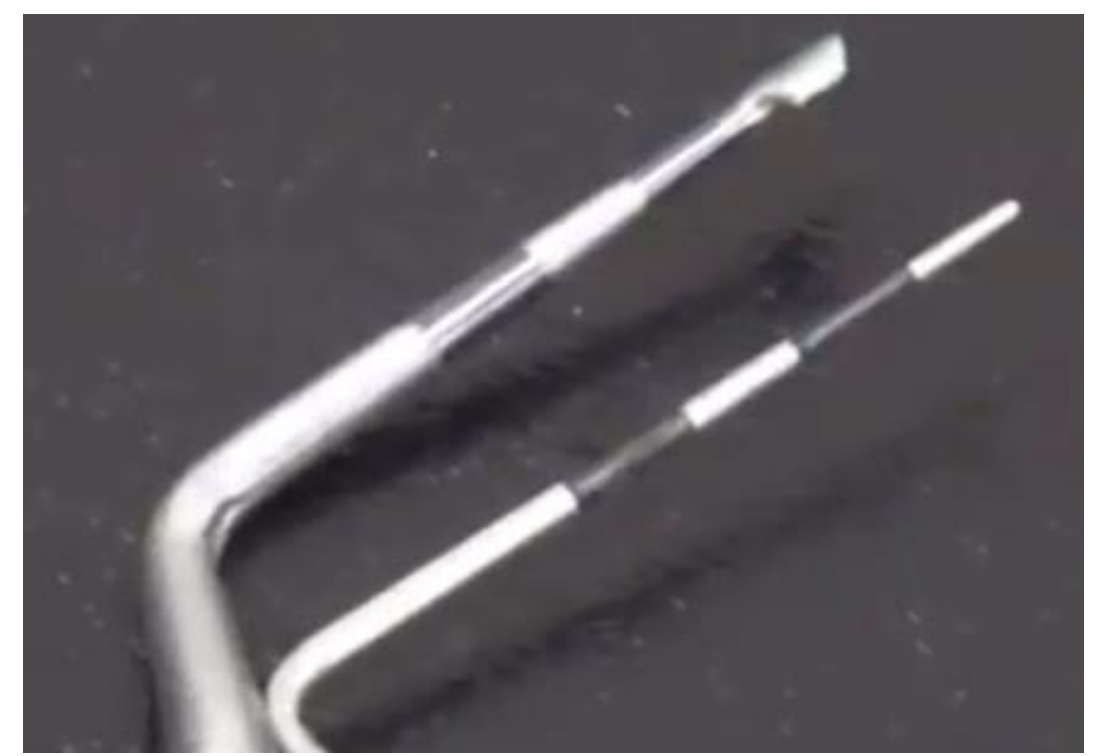

Figure 1: Probe $\mathrm{PCP} 12^{*}$ and parallel the new file. Note that the initial $3 \mathrm{~mm}$ correspond to the base of the instrument. *PCP 12 Probe - Hu-Friedy Manufacturing Company,Chicago, IL, USA

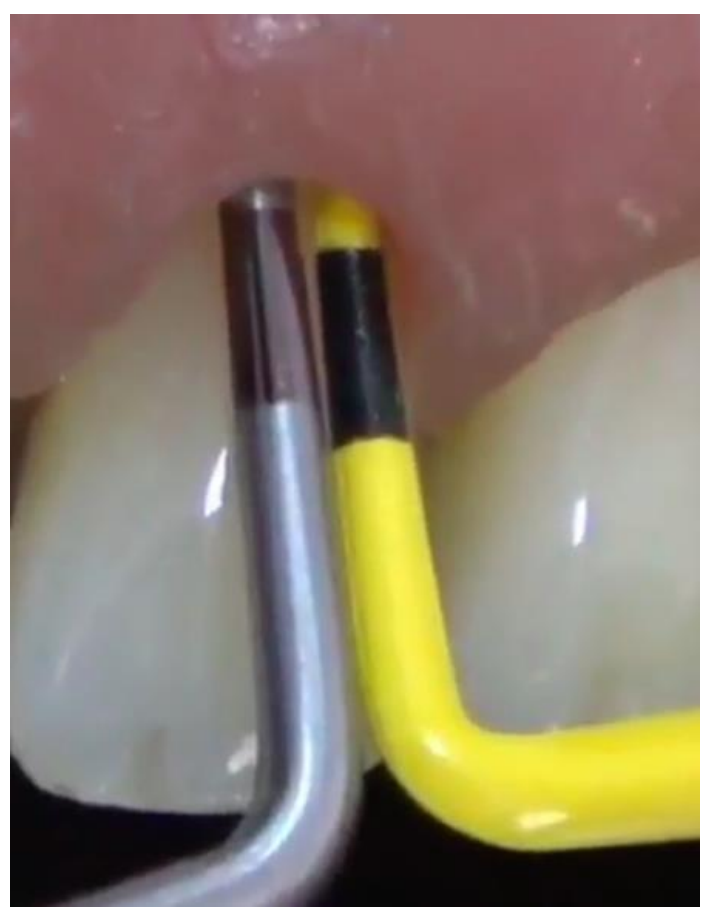

Figure 2: Buccal view showing Probe Perio** and parallel the new PHenriques file in $\mathrm{mm} .{ }^{* *}$ Perio View Probe -Hu-Friedy Manufacturing Company,Chicago, IL, USA 
Therefore, a specific small diameter (width of and its sharp edges in 270 degrees around the $0,7 \mathrm{~mm}$ ) mini PHenriques 6(Maxilar Molar) and active tip, reaching the root trunk, fornix and PHenriques $7^{\star}$ (Mandibular Molar) files, were neighbor's surfaces. They are extremely useful designed to instrument more easily this complex in Class II and especially Class III involvement region of respectively maxillary and mandibular and sharpening in the same way as conventional molar furcation. Consist of a series of 3 blades, files. [Figures 3-4]

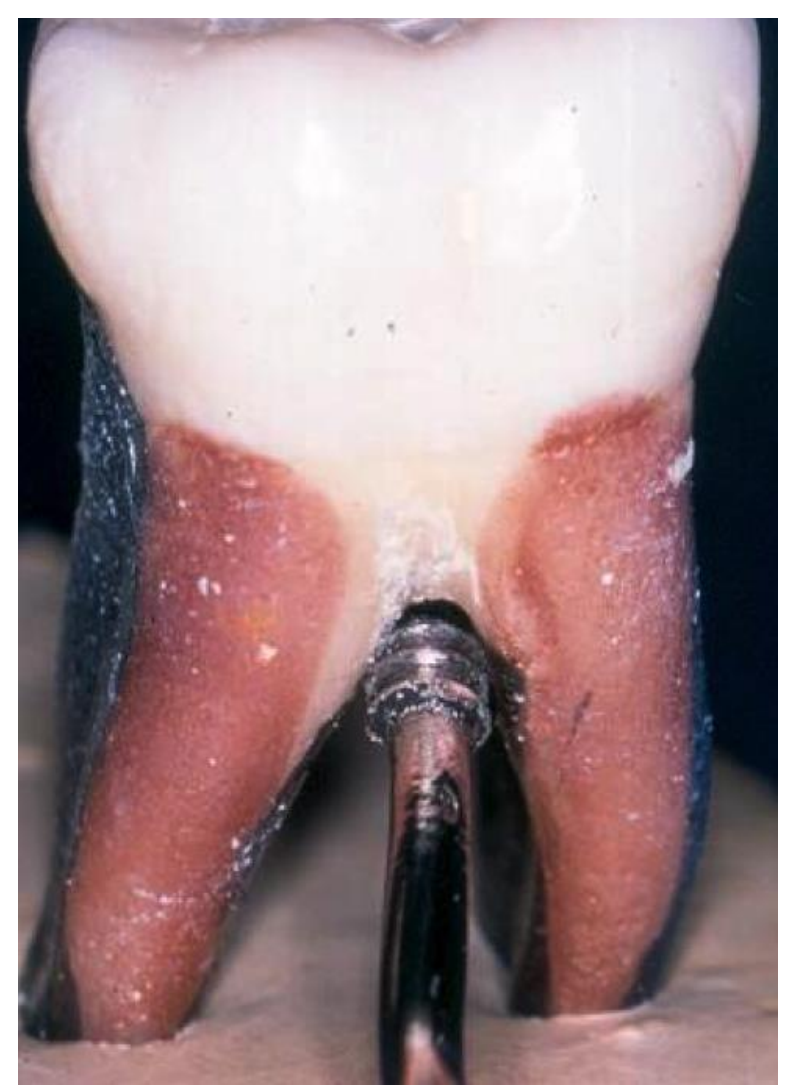

Figure 3: PHenriques $7^{* * *}$ in the molar Fornix region. Note the small diameter of the instrument ${ }^{\star * \star}$ Quinelato Surgical Instruments, Rio Claro, São Paulo, Brazil.

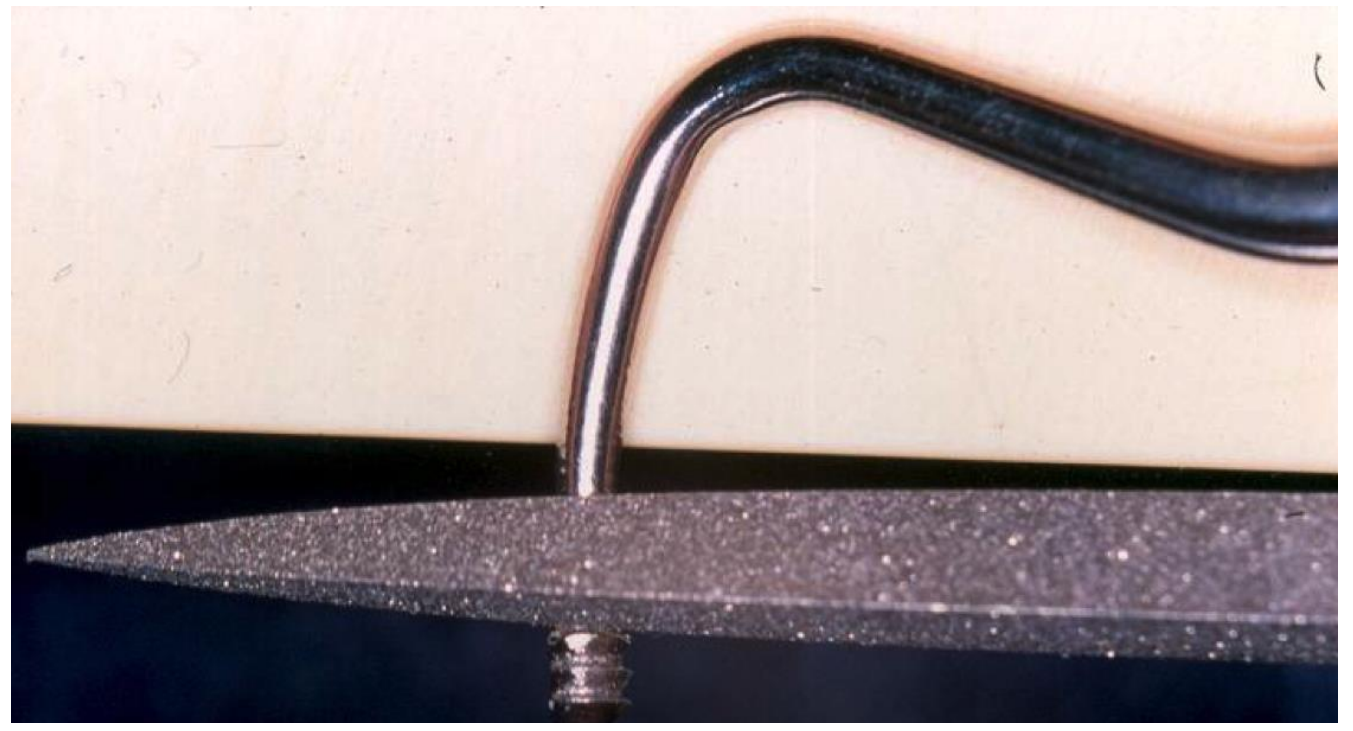

Figure 4: Sharpening file PHenriques $6^{\star * \star}{ }^{* *}$ Quinelato Surgical Instruments, Rio Claro, São Paulo, Brazil. 


\section{Conflict of Interest}

The authors declare that there is no conflict of interest in this article.

\section{References}

[1]. Hodge,K. Using files in periodontal therapy. Dimensions of Dental Hygiene. 2004;2(11):16, 18-

[2]. Pasquini R, Clark SM, Baradaran S, Adams DF. Periodontal files-a comparative study.J Periodontol. 1995;66:1040-1046.

[3]. Hoopla S. Files provide desirable results in patient treatment procedures. RDH. 1985;22-24.

[4]. Pattison AM, Pattison GL. Periodontal instrumentation transformed. Dimensions of Dental Hygiene. 2003;1(2):18-22.

[5]. Marcaccini AM, Pavanelo Â, Nogueira AVB, Souza JAC de, Porciúncula HF, Cirelli JA. Morfometria study of the root anatomy in furcation area of mandibular first molars. J. Appl. Oral Sci. 2012;20(1):76-81. 